Article

\title{
Novel Graphical Representation and Numerical Characterization of DNA Sequences
}

\author{
Chun $\mathrm{Li}^{1,2 * *}$, Wenchao Fei ${ }^{1}$, Yan Zhao ${ }^{1}$ and Xiaoqing $\mathrm{Yu}^{3}$ \\ 1 Department of Mathematics, Bohai University, Jinzhou 121013, China; feiwenchao90@163.com (W.F.); \\ zhaoyan_jinzh@126.com (Y.Z.) \\ 2 Research Institute of Food Science, Bohai University, Jinzhou 121013, China \\ 3 Department of Applied Mathematics, Shanghai Institute of Technology, Shanghai 201418, China; \\ xqyu@sit.edu.cn \\ * Correspondence: lichwun@163.com; Tel.: +86-416-3402166
}

Academic Editor: Yang Kuang

Received: 10 December 2015; Accepted: 14 February 2016; Published: 24 February 2016

\begin{abstract}
Modern sequencing technique has provided a wealth of data on DNA sequences, which has made the analysis and comparison of sequences a very important but difficult task. In this paper, by regarding the dinucleotide as a 2-combination of the multiset $\{\infty \cdot \mathrm{A}, \infty \cdot \mathrm{G}, \infty \cdot \mathrm{C}, \infty \cdot \mathrm{T}\}$, a novel 3-D graphical representation of a DNA sequence is proposed, and its projections on planes $(x, y),(y, z)$ and $(x, z)$ are also discussed. In addition, based on the idea of "piecewise function", a cell-based descriptor vector is constructed to numerically characterize the DNA sequence. The utility of our approach is illustrated by the examination of phylogenetic analysis on four datasets.
\end{abstract}

Keywords: 2-combination; graphical representation; cell-based vector; numerical characterization; phylogenetic analysis

\section{Introduction}

The rapid development of DNA sequencing techniques has resulted in explosive growth in the number of DNA primary sequences, and the analysis and comparison of biological sequences has become a topic of considerable interest in Computational Biology and Bioinformatics. The traditional measure for similarity analysis of DNA sequences is based on multiple sequence alignment, which uses dynamic programming techniques to identify the globally optimal alignment solution. However, the sequence alignment problem is NP-hard (non-deterministic polynomial-time hard), making it infeasible for dealing with large datasets [1]. To overcome the limitation, a lot of alignment-free approaches for sequence comparison have been proposed.

The basic idea behind most alignment-free methods is to characterize DNA by certain mathematical models derived for DNA sequence, rather than by a direct comparison of DNA sequences themselves. Graphical representation is deemed to be a simple and powerful tool for the visualization and analysis of bio-sequences. The earliest attempts at the graphical representation of DNA sequences were made by Hamori and Ruskin in 1983 [2]. Afterwards, a number of graphical representations were well developed by researchers. For instance, by assigning four directions defined by the positive/negative $x$ and $y$ coordinate axes to the four nucleic acid bases, Gates [3], Nandy [4,5], and Leong and Morgenthaler [6] introduced three different 2-D graphical representations, respectively. While Jeffrey [7] proposed a chaos game representation (CGR) of DNA sequences, in which the four corners of a selected square are associated with the four bases respectively. In 2000, Randic et al. [8] generalized these 2-D graphical representations to a 3-D graphical representation, in which the center of a cube is chosen as the origin of the Cartesian $(x, y, z)$ coordinate system, and the four corners with 
coordinates $(+1,-1,-1),(-1,+1,-1),(-1,-1,+1)$, and $(+1,+1,+1)$ are assigned to the four bases. Some other graphical representations of bio-sequences and their applications in the field of biological science and technology can be found in [9-24].

Numerical characterization is another useful tool for sequence comparison. One way to arrive at the numerical characterization of a DNA sequence is to associate the sequence with a vector whose components are related to $k$-words, including the single nucleotide, dinucleotide, trinucleotide, and so on [25-30]. In addition, the numerical characterization can be accomplished by associating with a graphical representation given by a curve in the space (or a plane) structural matrices, such as the Euclidean-distance matrix (ED), the graph theoretical distance matrix (GD), the quotient matrix (D/D, $\mathrm{M} / \mathrm{M}, \mathrm{L} / \mathrm{L}$ ), and their "higher order" matrices [8-18,31-33]. Once a matrix representation of a DNA sequence is given, some matrix invariants, e.g. the leading eigenvalues, can be used as descriptors of the sequence. This technique has been widely used in the field of biological science and medicine, and different types of matrices are defined to construct various invariants of DNA sequences. However, the order of these matrices is equal to $n$, the length of the DNA sequence considered. A problem we must face is that the calculation of these matrix invariants will become more and more difficult with larger $n$ values $[17,24,32]$.

In this paper, based on all of the 2-combinations of the multiset $\{\infty \cdot A, \infty \cdot G, \infty \cdot C, \infty \cdot T\}$, we propose a novel graphical representation of DNA sequences. Then, according to the idea of "piecewise function", we describe a particular scheme that transforms the graphical representation of DNA into a cell-based descriptor vector. The introduced vector leads to more simple characterizations and comparisons of DNA sequences.

\section{Methods}

\subsection{The 3-D Graphical Representation}

As we know, the four nucleic acid bases A, G, C, and T can be classified into three categories:

$$
\mathrm{R}=\{\mathrm{A}, \mathrm{G}\} / \mathrm{Y}=\{\mathrm{C}, \mathrm{T}\} ; \mathrm{M}=\{\mathrm{A}, \mathrm{C}\} / \mathrm{K}=\{\mathrm{G}, \mathrm{T}\} ; \mathrm{W}=\{\mathrm{A}, \mathrm{T}\} / \mathrm{S}=\{\mathrm{G}, \mathrm{C}\} .
$$

In fact, these groups are just all of the non-repetition 2-combinations of set $\{\mathrm{A}, \mathrm{G}, \mathrm{C}, \mathrm{T}\}$. If repetition is allowed, in other words, if we consider multiset $\{\infty \cdot A, \infty \cdot G, \infty \cdot C, \infty \cdot T\}$ instead of the set $\{A, G, C, T\}$, then the number of 2-combinations equals 10 (see Table 1 ).

Table 1. The 2-combinations of multiset $\{\infty \cdot A, \infty \cdot G, \infty \cdot C, \infty \cdot T\}$.

\begin{tabular}{ccccc}
\hline Base & A & G & C & T \\
\hline A & $\{\mathrm{A}, \mathrm{A}\}$ & $\{\mathrm{A}, \mathrm{G}\}$ & $\{\mathrm{A}, \mathrm{C}\}$ & $\{\mathrm{A}, \mathrm{T}\}$ \\
$\mathrm{G}$ & - & $\{\mathrm{G}, \mathrm{G}\}$ & $\{\mathrm{G}, \mathrm{C}\}$ & $\{\mathrm{G}, \mathrm{T}\}$ \\
$\mathrm{C}$ & - & - & $\{\mathrm{C}, \mathrm{C}\}$ & $\{\mathrm{C}, \mathrm{T}\}$ \\
$\mathrm{T}$ & - & - & - & $\{\mathrm{T}, \mathrm{T}\}$ \\
\hline
\end{tabular}

Let $V$ be a regular tetrahedron whose center is at the origin $O=(0,0,0) . \quad V_{1}=(+1,+1,+1)$, $V_{2}=(-1,-1,+1), V_{3}=(+1,-1,-1)$, and $V_{4}=(-1,+1,-1)$ are its four vertices. To each of the vertices we assign one of the four nucleic acid bases A, C, G and T. Moreover, to the midpoint of the line segment $A C$ we assign $M$, and $K$ to the midpoint of the line segment $G T, R$ to that of the line segment $A G, Y$ to that of the line segment $\mathrm{CT}, \mathrm{W}$ to that of the line segment $\mathrm{AT}$, and $\mathrm{S}$ to that of the line segment $\mathrm{CG}$. We thus obtain ten fixed directions: $\overrightarrow{O A}, \overrightarrow{O C}, \overrightarrow{O G}, \overrightarrow{O T}, \overrightarrow{O M}, \overrightarrow{O K}, \overrightarrow{O R}, \overrightarrow{O Y}, \overrightarrow{O W}, \overrightarrow{O S}$, based on which we can derive ten unit vectors:

$$
r_{A}=\frac{1}{\|\overrightarrow{O A}\|} \cdot \overrightarrow{O A}, r_{C}=\frac{1}{\|\overrightarrow{O C}\|} \cdot \overrightarrow{O C}, \ldots, r_{S}=\frac{1}{\|\overrightarrow{O S}\|} \cdot \overrightarrow{O S}
$$


Obviously, the ten unit vectors are ten points on a unit sphere.

An idea arises naturally: each of the ten 2-combinations can be associated with one of the ten unit vectors. In detail, we have

$$
\begin{aligned}
& \{A, A\} \leftarrow r_{A},\{A, G\} \leftarrow r_{R},\{A, C\} \leftarrow r_{M},\{A, T\} \leftarrow r_{W}, \\
& \{G, G\} \leftarrow r_{G},\{G, C\} \leftarrow r_{S},\{G, T\} \leftarrow r_{K}, \\
& \{C, C\} \leftarrow r_{C},\{C, T\} \leftarrow r_{Y},\{T, T\} \leftarrow r_{T} .
\end{aligned}
$$

To obtain the spatial curve of a DNA sequence, we move a unit length in the direction that the above assignment dictates. Taking sequence segment ATGGTGCACCTGACTCCTGATCTGGTA as an example, we inspect it by stepping two nucleotides at a time. Starting from the origin $O=(0,0,0)$, we move in the direction dictated by the first dinucleotide AT, $r_{W}$, and arrive at $P_{1}$, the first point of the 3 -D curve. From this point, we move in the direction dictated by the second dinucleotide TG, $r_{K}$, and arrive at the second point $P_{2}$. From here we move in the direction dictated by the third dinucleotide GG, $r_{G}$, and come to the third point $P_{3}$. Continuation of this process is illustrated in Table 2, and the corresponding 3-D graphical representation is shown in Figure 1.

Table 2. Cartesian 3-D coordinates for the sequence ATGGTGCACCTGACTCCTGATCTGGTA.

\begin{tabular}{ccccc}
\hline Point & Dinucleotide & $x$ & $y$ & $z$ \\
\hline 1 & AT & 0 & 1 & 0 \\
2 & TG & 0 & 1 & -1 \\
3 & GG & 0.5774 & 0.4226 & -1.5774 \\
4 & GT & 0.5774 & 0.4226 & -2.5774 \\
5 & TG & 0.5774 & 0.4226 & -3.5774 \\
6 & GC & 0.5774 & -0.5774 & -3.5774 \\
7 & CA & 0.5774 & -0.5774 & -2.5774 \\
8 & AC & 0.5774 & -0.5774 & -1.5774 \\
9 & CC & 0 & -1.1547 & -1 \\
10 & CT & -1 & -1.1547 & -1 \\
$\ldots$ & $\ldots$ & $\ldots$ & $\ldots$ & $\ldots$ \\
\hline
\end{tabular}

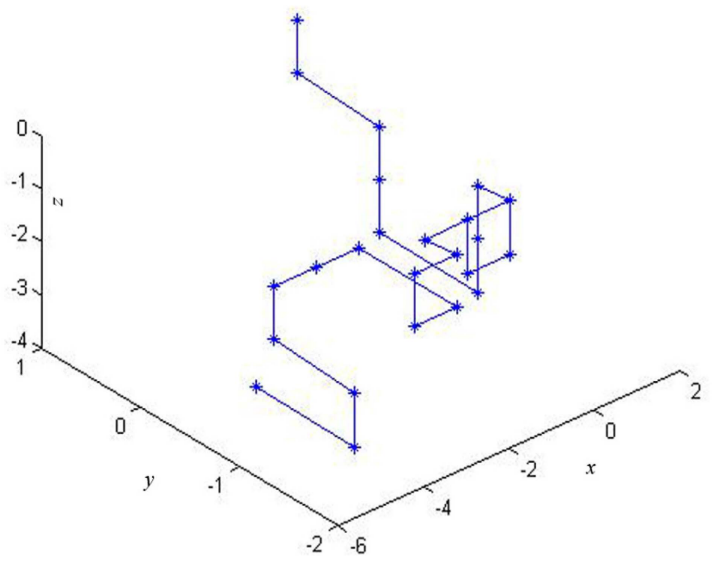

Figure 1. 3-D graphical representation of the sequence ATGGTGCACCTGACTCCTGATCTGGTA.

As the characterization of a research object, a good visualization representation should allow us to see a pattern that may be difficult or impossible to see when the same data is presented in its original form. In order to provide a direct insight into the local and global characteristics of a DNA sequence, the proposed 3-D curve can be projected on planes $(x, y),(y, z)$ or $(x, z)$, and thus three different 2-D graphical representations will be yielded. Figure 2 shows the projections of 3-D curves of 18 different DNA sequences listed in Table 3. 


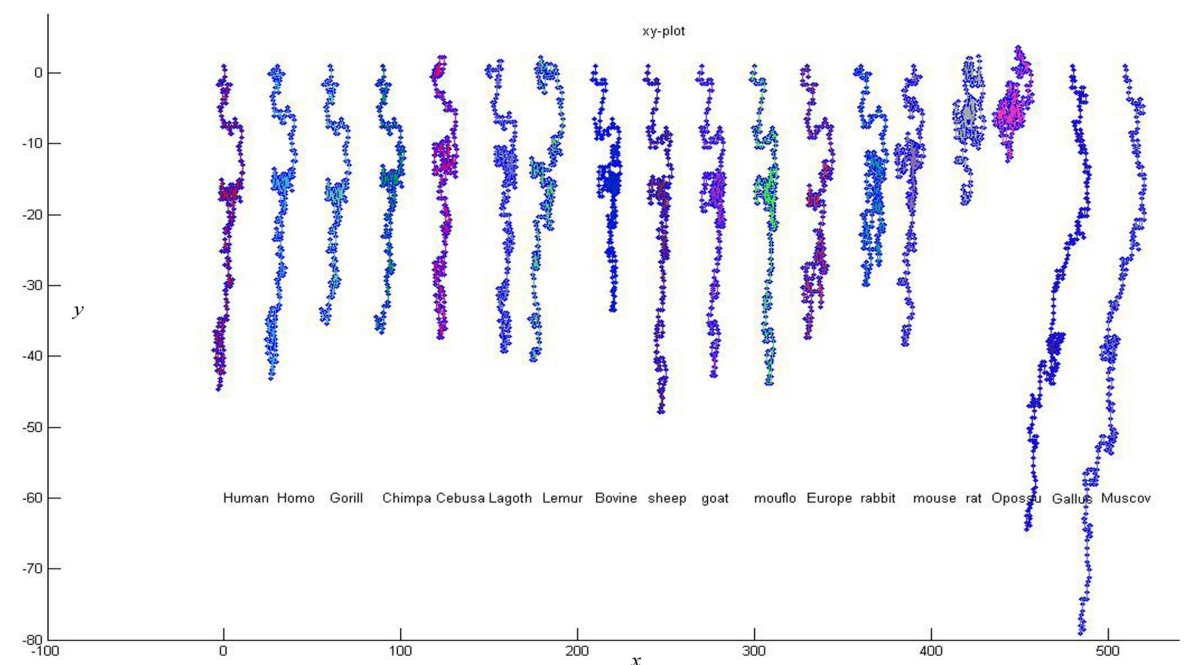

(a)

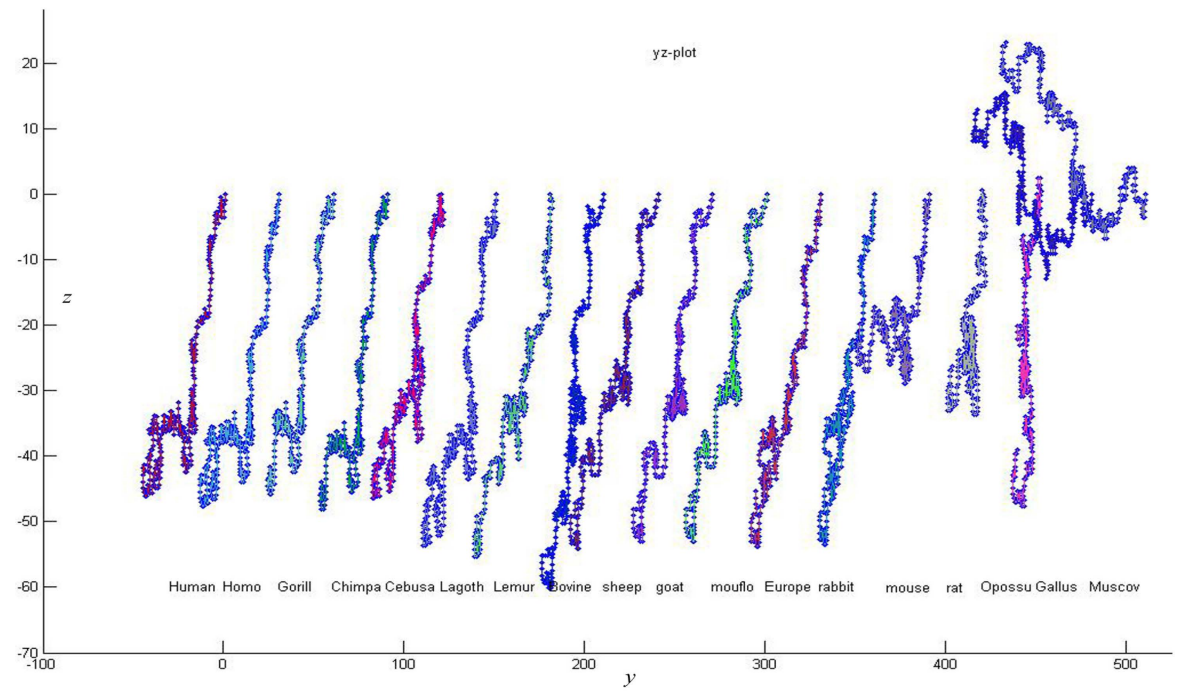

(b)

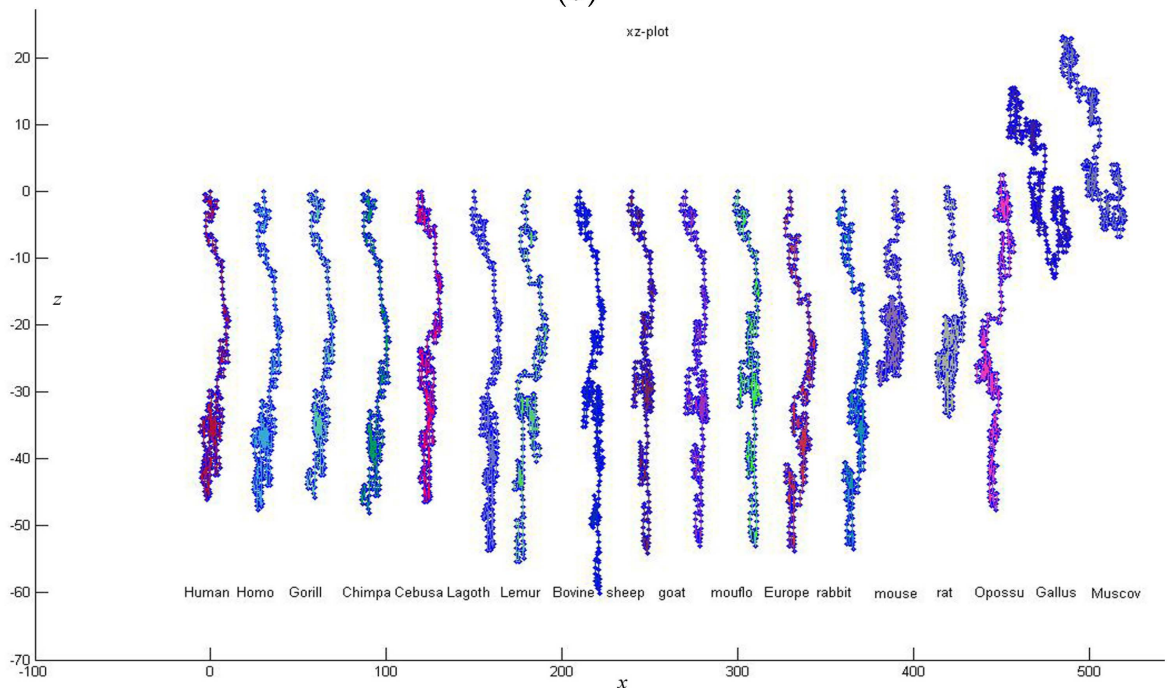

(c)

Figure 2. (a) The projection on the $x y$-plane of 3-D curves of 18 DNA sequences; (b) The projection on the $y z$-plane of 3-D curves of 18 DNA sequences; (c) The projection on the $x z$-plane of 3-D curves of 18 DNA sequences. 
Table 3. The CDS (Coding DNA Sequence) of $\beta$-globin gene of 18 species.

\begin{tabular}{cccc}
\hline No. & Species & AC (GenBank) & Location \\
\hline 1 & Human & U01317 & join $(62187 . .62278,62409 . .62631,63482 . .63610)$ \\
2 & Homo & AF007546 & join $(180 . .271,402 . .624,1475 . .1603)$ \\
3 & Gorilla & X61109 & join $(4538 . .4630,4761 . .4982,5833 . .>5881)$ \\
4 & Chimpanzee & X02345 & join $(4189 . .4293,4412 . .4633,5484 . .>5532)$ \\
5 & Lemur & M15734 & join $(154 . .245,376 . .598,1467 . .1595)$ \\
6 & CebusaPella & AY279115 & join $(946 . .1037,1168 . .1390,2218 . .2346)$ \\
7 & LagothrixLagotricha & AY279114 & join $(952 . .1043,1174.1396,2227 . .2355)$ \\
8 & Bovine & X00376 & join $(278 . .363,492 . .714,1613 . .1741)$ \\
9 & Goat & M15387 & join $(279 . .364,493 . .715,1621 . .1749)$ \\
10 & Sheep & DQ352470 & join $(238 . .323,452 . .674,1580 . .1708)$ \\
11 & Mouflon & DQ352468 & join $(238 . .323,452 . .674,1578 . .1706)$ \\
12 & European hare & Y00347 & join $(1485 . .1576,1703 . .1925,2492 . .2620)$ \\
13 & Rabbit & V00882 & join $(277 . .368,495 . .717,1291 . .1419)$ \\
14 & Mouse & V00722 & join $(275 . .367,484 . .705,1334 . .1462)$ \\
15 & Rat & X06701 & join $(310 . .401,517.739,1377 . .>1505)$ \\
16 & Opossum & J03643 & join $(467 . .558,672 . .894,2360 . .2488)$ \\
17 & Gallus & V00409 & join $(465 . .556,649 . .871,1682 . .1810)$ \\
18 & Muscovyduck & X15739 & join $(291 . .382,495 . .717,1742 . .1870)$ \\
\hline
\end{tabular}

It is easy to see that, in each projection, the trend of curves of the two non-mammals (Gallus, Muscovy duck) is distinguished from that of the mammals. On the other hand, the Primates species are similar to one another, so it is with the curves of bovine, sheep, goat, and mouflon. Also, the curves of rabbit and European hare show their great similarity. In addition, both Figure $2 \mathrm{~b}$, the projection on $y z$-plane, and Figure 2c, the projection on $x z$-plane, show opossum has relatively low similarity with the remaining mammals, while mouse and rat look similar to each other because both of their curves wind themselves into a mass and need a relatively small space.

\subsection{Numerical Characterization of DNA Sequences}

The graphical representations not only offer the visual inspection of data, helping in recognizing major differences among DNA sequences, but also provide with the numerical characterization that facilitates quantitative comparisons of DNA sequences. One way to arrive at the numerical characterization of a DNA sequence is to convert its graphical representation into some structural matrices, and use matrix invariants, e.g., the leading eigenvalues, as descriptors of the DNA sequence [8-18,31,32]. It is expected that effective invariants will emerge and enable to uniquely characterize the sequences considered. However, the difficulties associated with computing various parameters for very large matrices that are natural for long sequences have restricted the numerical characterizations, for instance, leading eigenvalues and the like $[17,24]$. The search for novel descriptors may be an endless project. The art is in finding useful descriptors, and those that have plausible structural interpretation, at least within the model considered [8]. In this section, we bypass the difficulty of calculating the invariants like the leading eigenvalue and propose a novel descriptor to numerically characterize a DNA sequence.

As described above, the pattern, including shape and trend, of curves for the 18 DNA sequences provides useful information in an efficient way. This inspires us to numerically characterize a DNA sequence with an idea of "piecewise function" as below.

For a given 3-D graphical representation with $n$ vertices, by the order in which these vertices appear in the curve, we partition it into $K$ parts, each of which is called a cell. All the cells contain $m=\left\lfloor\frac{n}{K}\right\rfloor$ vertices except the last one. For the $i$-th cell, $i=1,2, \ldots, K$, the geometric center $U_{i}=\left(x_{i}, y_{i}, z_{i}\right)$ is viewed as its respective. Then we have

$$
\overrightarrow{U_{i-1}} U_{i}=\left(x_{i}-x_{i-1}, y_{i}-y_{i-1}, z_{i}-z_{i-1}\right)
$$


where $U_{0}=(0,0,0)$. It is not difficult to find that $\overrightarrow{U_{i-1}} U_{i}$ reflects a certain "growing trend" of these cells. For convenience, we call $\overrightarrow{U_{i-1}} U_{i}$ the trend-point. On the basis of the $K$ trend-points, a DNA sequence can be characterized by a $3 \mathrm{~K}$-dimensional vector $V_{t p}$ :

$$
\begin{aligned}
V_{t p}= & \left(x_{1}-x_{0}, x_{2}-x_{1}, \cdots, x_{k}-x_{k-1},\right. \\
& y_{1}-y_{0}, y_{2}-y_{1}, \cdots, y_{k}-y_{k-1} \\
& \left.z_{1}-z_{0}, z_{2}-z_{1}, \cdots, z_{k}-z_{k-1}\right)
\end{aligned}
$$

In this paper, $K$ is determined by round $\left(\log _{4} \frac{\bar{L}}{2 \sqrt{2}}\right)$, where $\bar{L}=\frac{1}{N} \sum_{j=1}^{N}\left|s_{j}\right|, N$ is the cardinality of the dataset $\Omega$ considered, and $\left|s_{j}\right|$ stands for the length of sequence $s_{j} \in \Omega$. Taking for example the two non-mammals of the 18 species, the corresponding vectors can be calculated as

$$
\begin{gathered}
V_{\text {Gallus }}=(4.524,-9.588,-5.546,-10.962,-9.234,-20.304, \\
\quad-9.824,-12.093,-4.087,-0.450,10.255,5.615), \\
V_{\text {MDuck }}=(6.186,-10.593,-3.440,-12.511,-10.639,-21.519, \\
\quad-12.987,-18.351,-1.244,0.498,10.478,9.325) .
\end{gathered}
$$

\section{Results and Discussion}

In this section, we will illustrate the use of the proposed cell-based descriptor $V_{t p}$ of a DNA sequence. For any two sequences $S_{a}$ and $S_{b}$, suppose their descriptor vectors are $a=\left(a_{1}, a_{2}, \cdots, a_{3 k}\right)$ and $b=\left(b_{1}, b_{2}, \cdots, b_{3 k}\right)$, respectively. Then, their similarity can be examined by the following Euclidean distance. Clearly, the smaller the Euclidean distance is, the more similar the two DNA sequences are.

$$
d(a, b)=\sqrt{\sum_{j=1}^{3 k}\left(a_{j}-b_{j}\right)^{2}}
$$

Firstly, we give a comparison for CDS (Coding DNA Sequence) of $\beta$-globin gene of 18 species listed in Table 3. The lengths of the 18 sequences are about $434 \mathrm{bp}$. Thus $K$ is taken to be 4 , and each of these sequences is converted into a 12-D vector. According to Equation (7), we calculate the distance between any two of the 18 DNA sequences. Then an $18 \times 18$ real symmetric matrix $D_{18}$ is obtained. On the basis of $D_{18}$, a phylogenetic tree (see Figure 3) is constructed using UPGMA (Unweighted Pair Group Method with Arithmetic Mean) program included in MEGA4 [34]. Observing Figure 3, we find that the CDS are more similar for Primate group \{Gorilla, Chimpanzee, Human, Homo, CebusaPella, LagothrixLagotricha, Lemur\}, Cetartiodactyla group \{bovine, sheep, goat, mouflon\}, Lagomorpha group $\{$ Rabbit, European hare\}, and Rodentia group \{mouse, rat\}, respectively. On the other hand, CDS of the two kinds of non-mammals \{Gallus, Muscovy duck\} are very dissimilar to the mammals because they are grouped into an independent branch. This is analogous to that reported in the literature $[8,12,14,31]$, and the relationship of these species detected by their graphical representations as well. From this result, a conclusion one can draw is that the cell-based descriptors of the new graphical representation may suffice to characterize DNA sequences. 


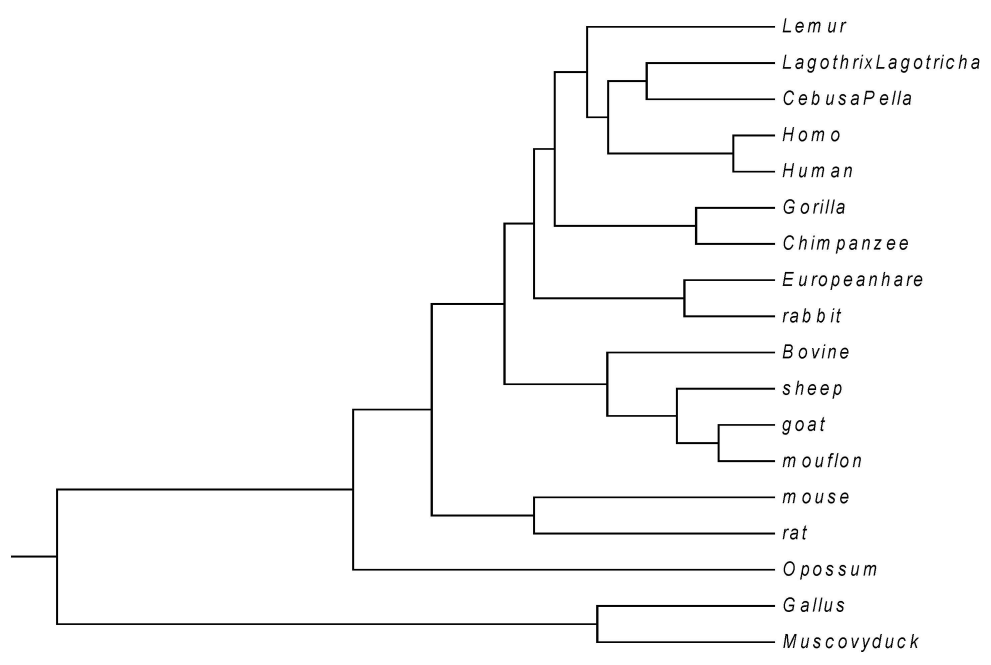

Figure 3. The relationship tree of 18 species.

In order to further illustrate the effectiveness of our method, we test it by phylogenetic analysis on other three datasets: one consists of mitochondrial cytochrome oxidase subunit I (COI) genes of nine butterflies, another includes $\mathrm{S}$ segments of 32 hantaviruses (HVs), and the last is composed of 70 complete mitogenomes (mitochondrial genomes). For convenience, we denote the three datasets by COI, HV and mitogenome, respectively. In the COI dataset (see Table 4), which is taken from Yang et al. [12], eight belong to the Catopsilia genus and one belongs to Appias genus, which is used as the out-group. The average length of these COI gene sequences is $661 \mathrm{bp}$, and thus $K$, the number of cells, is calculated as 4 . According to the method mentioned above, a distance matrix is constructed, and then a phylogenetic tree (see Figure 4 ) is generated. Figure 4 shows that the five pomona sub-species have relatively high similarity with each other, while the two pyranthe sub-species cluster together. In addition, scylla sub-species is situated at an independent branch, whereas the Appias lyncida stays outside of all the Catopsilia. This result is consistent with that reported in [12,35].

Table 4. The COI (cytochrome oxidase subunit I) genes of nine butterflies.

\begin{tabular}{ccccc}
\hline NO. & Species & Code & AC (GenBank) & Region \\
\hline 1 & C.pomona pomona f.pomona & PA & GU446662 & Yexianggu, Yunnan \\
2 & C.pomona pomona f.hilaria & HI & GU446664 & Yexianggu, Yunnan \\
3 & C.pomona pomona f.crocale & CR & GU446663 & Menglun, Yunnan \\
4 & C.pomona pomona f.catilla & CA & GU446666 & Daluo, Yunnan \\
5 & C.pomona pomona f.jugurtha & JU & GU446665 & Daluo, Yunnan \\
6 & C.scylla scylla & CS & GU446667 & Yinggeling, Hainan \\
7 & C.pyranthe pyranthe & CP & GU446668 & Daluo, Yunnan \\
8 & C.pyranthe chryseis & CH & GU446669 & Yinggeling, Hainan \\
9 & Appias lyncida & - & GU446670 & Bawangling, Hainan \\
\hline
\end{tabular}

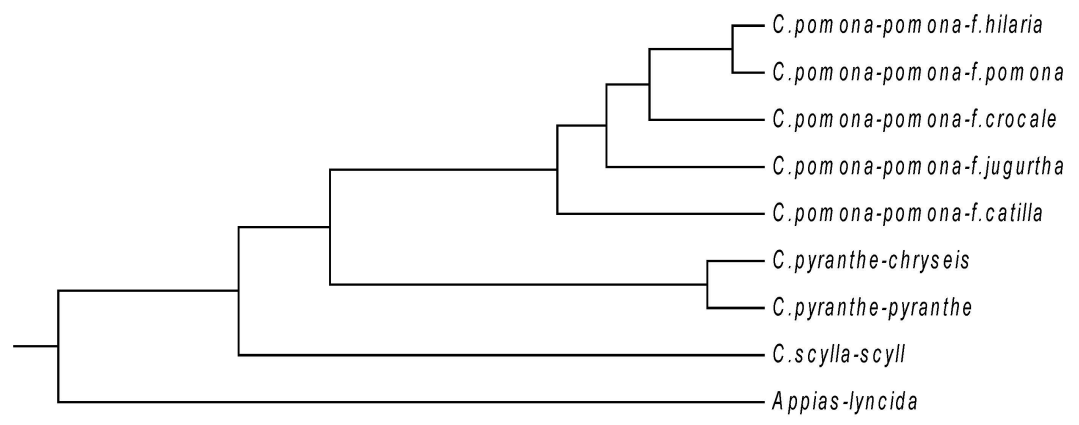

Figure 4. The relationship tree of nine COI (cytochrome oxidase subunit I) gene sequences. 
The hantavirus (HV), which is named for the Hantan River area in South Korea, is a relatively newly discovered RNA virus in the family Bunyaviridae. This kind of virus normally infects rodents and does not cause disease in these hosts. Humans may be infected with HV, and some HV strains could cause severe, sometimes fatal, diseases in humans, such as HFRS (hantavirus hemorrhagic fever with renal syndrome) and HPS (hantavirus pulmonary syndrome). The later occurred in North and South America, while the former mainly in Eurasia [12,36]. In Eastern Asia, particularly in China and Korea, the viruses that cause HFRS mainly include Hantaan (HTN) and Seoul (SEO) viruses, while Puumala (PUU) virus is found in Western Europe, Russia and northeastern China. The HV dataset analyzed in this paper includes $32 \mathrm{HV}$ sequences. Phlebovirus (PV) is another genus of the family Bunyaviridae. Here, two PV strains KF297911 and KF297914 are used as the out-group. The name, accession number, type, and region of the 34 sequences are described in Table 5 . The lengths of these sequences are in the range of $1.30-1.88 \mathrm{kbp}$. Thus $K$ is calculated as 5 , and each of the 34 viruses is converted into a 15-D vector. The phylogenetic tree constructed by our method is shown in Figure 5.

Table 5. Sequence information of S segment of hantavirus.

\begin{tabular}{|c|c|c|c|c|}
\hline No. & Strain & AC (GenBank) & Type & Region \\
\hline 1 & CGRn53 & EF990907 & HTNV & Guizhou \\
\hline 2 & CGRn5310 & EF990906 & HTNV & Guizhou \\
\hline 3 & CGRn93MP8 & EF990905 & HTNV & Guizhou \\
\hline 4 & CGRn8316 & EF990903 & HTNV & Guizhou \\
\hline 5 & CGRn9415 & EF990902 & HTNV & Guizhou \\
\hline 6 & CGRn93P8 & EF990904 & HTNV & Guizhou \\
\hline 7 & CGHu3612 & EF990909 & HTNV & Guizhou \\
\hline 8 & CGHu3614 & EF990908 & HTNV & Guizhou \\
\hline 9 & $\mathrm{Z} 10$ & AF184987 & HTNV & Shengzhou \\
\hline 10 & Z5 & EF103195 & HTNV & Shengzhou \\
\hline 11 & NC167 & AB027523 & HTNV & Anhui \\
\hline 12 & CGAa4MP9 & EF990915 & HTNV & Guizhou \\
\hline 13 & CGAa4P15 & EF990914 & HTNV & Guizhou \\
\hline 14 & CGAa1011 & EF990913 & HTNV & Guizhou \\
\hline 15 & CGAa1015 & EF990912 & HTNV & Guizhou \\
\hline 16 & H5 & AB127996 & HTNV & Heilongjiang \\
\hline 17 & $76-118$ & M14626 & HTNV & $\begin{array}{l}\text { South } \\
\text { Korea }\end{array}$ \\
\hline 18 & Gou3 & AF184988 & SEOV & Jiande \\
\hline 19 & ZJ5 & FJ753400 & SEOV & Jiande \\
\hline 20 & $80-39$ & AY273791 & SEOV & $\begin{array}{l}\text { South } \\
\text { Korea }\end{array}$ \\
\hline 21 & SR11 & M34881 & SEOV & Japan \\
\hline 22 & K24-e7 & AF288653 & SEOV & Xinchang \\
\hline 23 & K24-v2 & AF288655 & SEOV & Xinchang \\
\hline 24 & Z37 & AF187082 & SEOV & Wenzhou \\
\hline 25 & ZT10 & AY766368 & SEOV & Tiantai \\
\hline 26 & ZT71 & AY750171 & SEOV & Tiantai \\
\hline 27 & K27 & L08804 & PUUV & Russia \\
\hline 28 & P360 & L11347 & PUUV & Russia \\
\hline 29 & Sotkamo & X61035 & PUUV & Finland \\
\hline 30 & Fusong843-06 & EF488805 & PUUV & Jilin \\
\hline 31 & Fusong199-05 & EF488803 & PUUV & Jilin \\
\hline 32 & Fusong900-06 & EF488806 & PUUV & Jilin \\
\hline 33 & 91045-AG & KF297911 & PV & Iran \\
\hline 34 & I-58 & KF297914 & PV & Iran \\
\hline
\end{tabular}




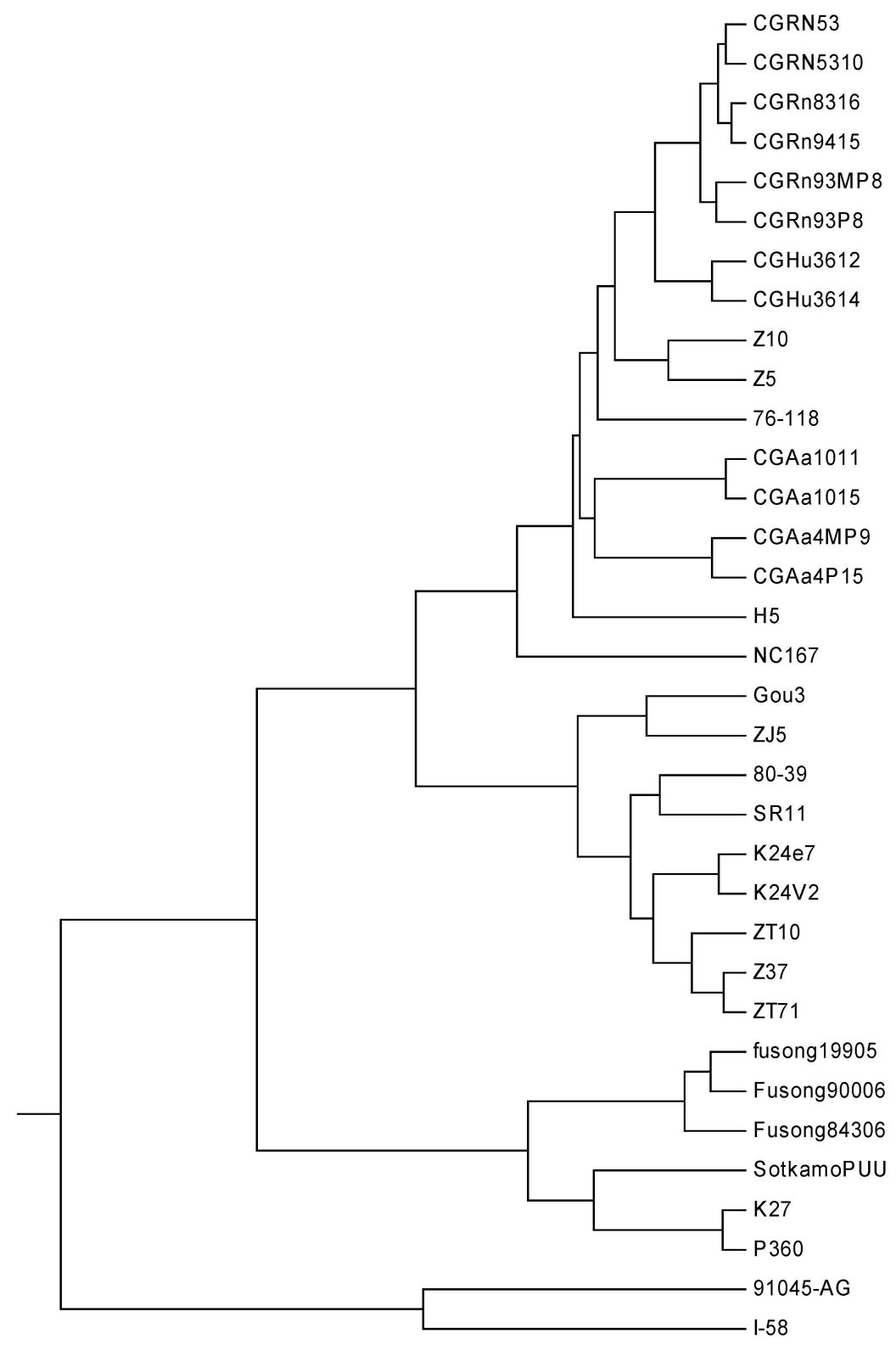

Figure 5. The relationship tree of 34 viruses.

From Figure 5, we find that the two PV strains form an independent branch, which can be distinguished easily from the HV strains, while the $32 \mathrm{HVs}$ are grouped into three separate branches: the strains belonging to PUUV are clearly clustered together, the strains belonging to SEOV appear to cluster together, and so do the ones belonging to HTNV. A closer look at the subtree of HTNV, all CGRn strains whose host is Rattus norvegicus tend to cluster together, so it is with the CGHu strains whose host is Homo sapiens. In addition, all the four CGAa strains whose host is Apodemus agrarius are grouped closely. Needless to say, the phylogeny is not only closely related to the isolated regions, but also has certain relationship with the host. This result is similar to that reported in [12,37].

The mitogenome dataset comprises 70 complete mitochondrial genomes of Eukaryota. The name, accession number, and genome length are listed in Table 6. Among them, two species (Argopecten irradians irradians and Argopecten purpuratus) belong to family Pectinidae are used as the out-group. Four species belong to the Order Caudata under the Class Amphibia, while four species belong to the Order Anura under the same Class. The remaining belongs to the Class Actinopterygii. The average length of the 70 genome sequences is about $16817 \mathrm{bp}$. Thus, $K$ is calculated as 6 , and each 
of these genome sequences is converted into an 18-D vector. The phylogenetic tree constructed by our method is shown in Figure 6. It is easy to see from Figure 6 that the two Pectinidae species stay outside of the others, while the four Hynobiidae species and four Ranidae species form an independent branch. In the subtree of the Class Actinopterygii, the 60 genomes are separated into six groups: group 1 corresponds to genus Anguilla under family Anguillidae; group 2 includes genera Bangana and Acrossocheilus under family Cyprinidae; group 3 includes genera Brachymystax and Hucho under family Salmonidae; group 4 is genus Alepocephalus under family Alepocephalidae; group 5 is the family of Clupeidae; group 6 includes genera Trichiurus, Amphiprion and Apolemichthys under Acanthomorphata. This result agrees well with the established taxonomic groups. In addition, we make a comparison for the 70 genome sequences by using ClustalX2.1 [38], and the corresponding tree is shown in Figure 7. Observing Figure 7, we find that the tree includes four branches: the outside is the Argopecten branch, the following is Babina, then Batrachuperus, and the subtree consisting of the other 60 species. A closer look at the subtree shows that Trichiurus is distinguished from the remaining, which seems to be a disappointing phenomenon in the evolutionary sense.

Table 6. Sequence information of 70 complete mitogenomes.

\begin{tabular}{|c|c|c|c|}
\hline No. & Genome & AC (GenBank) & Length \\
\hline 1 & Acrossocheilus barbodon & NC_022184 & 16596 \\
\hline 2 & Acrossocheilus beijiangensis & NC_028206 & 16600 \\
\hline 3 & Acrossocheilus fasciatus & NC_023378 & 16589 \\
\hline 4 & Acrossocheilus hemispinus & NC_022183 & 16590 \\
\hline 5 & Acrossocheilus kreyenbergii & NC_024844 & 16849 \\
\hline 6 & Acrossocheilus monticola & NC_022145 & 16599 \\
\hline 7 & Acrossocheilus parallens & NC_026973 & 16592 \\
\hline 8 & Acrossocheilus stenotaeniatus & NC_024934 & 16594 \\
\hline 9 & Acrossocheilus wenchowensis & NC_020145 & 16591 \\
\hline 10 & Alepocephalus agassizii & NC_013564 & 16657 \\
\hline 11 & Alepocephalus australis & NC_013566 & 16640 \\
\hline 12 & Alepocephalus bairdii & NC_013567 & 16637 \\
\hline 13 & Alepocephalus bicolor & NC_011012 & 16829 \\
\hline 14 & Alepocephalus productus & NC_013570 & 16636 \\
\hline 15 & Alepocephalus tenebrosus & NC_004590 & 16644 \\
\hline 16 & Alepocephalus umbriceps & NC_013572 & 16640 \\
\hline 17 & Alosa alabamae & NC_028275 & 16708 \\
\hline 18 & Alosa alosa & NC_009575 & 16698 \\
\hline 19 & Alosa pseudoharengus & NC_009576 & 16646 \\
\hline 20 & Alosa sapidissima & NC_014690 & 16697 \\
\hline 21 & Amphiprion bicinctus & NC_016701 & 16645 \\
\hline 22 & Amphiprion clarkia & NC_023967 & 16976 \\
\hline 23 & Amphiprion frenatus & NC_024840 & 16774 \\
\hline 24 & Amphiprion ocellaris & NC_009065 & 16649 \\
\hline 25 & Amphiprion percula & NC_023966 & 16645 \\
\hline 26 & Amphiprion perideraion & NC_024841 & 16579 \\
\hline 27 & Amphiprion polymnus & NC_023826 & 16804 \\
\hline 28 & Anguilla anguilla & NC_006531 & 16683 \\
\hline 29 & Anguilla australis & NC_006532 & 16686 \\
\hline 30 & Anguilla australis schmidti & NC_006533 & 16682 \\
\hline 31 & Anguilla bengalensis labiata & NC_006543 & 16833 \\
\hline 32 & Anguilla bicolor bicolor & NC_006534 & 16700 \\
\hline 33 & Anguilla bicolor pacifica & NC_006535 & 16693 \\
\hline 34 & Anguilla celebesensis & NC_006537 & 16700 \\
\hline 35 & Anguilla dieffenbachia & NC_006538 & 16687 \\
\hline 36 & Anguilla interioris & NC_006539 & 16713 \\
\hline 37 & Anguilla japonica & NC_002707 & 16685 \\
\hline 38 & Anguilla luzonensis (Philippine eel) & NC_011575 & 16635 \\
\hline
\end{tabular}


Table 6. Cont.

\begin{tabular}{|c|c|c|c|}
\hline No. & Genome & AC (GenBank) & Length \\
\hline 39 & Anguilla luzonensis (freshwater eel) & NC_013435 & 16632 \\
\hline 40 & Anguilla malgumora & NC_006536 & 16550 \\
\hline 41 & Anguilla marmorata & NC_006540 & 16745 \\
\hline 42 & Anguilla megastoma & NC_006541 & 16714 \\
\hline 43 & Anguilla mossambica & NC_006542 & 16694 \\
\hline 44 & Anguilla nebulosa nebulosa & NC_006544 & 16707 \\
\hline 45 & Anguilla obscura & NC_006545 & 16704 \\
\hline 46 & Anguilla reinhardtii & NC_006546 & 16690 \\
\hline 47 & Anguilla rostrata & NC_006547 & 16678 \\
\hline 48 & Apolemichthys armitagei & NC_027857 & 16551 \\
\hline 49 & Apolemichthys griffisi & NC_027592 & 16528 \\
\hline 50 & Apolemichthys kingi & NC_026520 & 16816 \\
\hline 51 & Argopecten irradians irradians & NC_012977 & 16211 \\
\hline 52 & Argopecten purpuratus & NC_027943 & 16270 \\
\hline 53 & Babina adenopleura & NC_018771 & 18982 \\
\hline 54 & Babina holsti & NC_022870 & 19113 \\
\hline 55 & Babina okinavana & NC_022872 & 19959 \\
\hline 56 & Babina subaspera & NC_022871 & 18525 \\
\hline 57 & Bangana decora & NC_026221 & 16607 \\
\hline 58 & Bangana tungting & NC_027069 & 16543 \\
\hline 59 & Batrachuperus londongensis & NC_008077 & 16379 \\
\hline 60 & Batrachuperus pinchonii & NC_008083 & 16390 \\
\hline 61 & Batrachuperus tibetanus & NC_008085 & 16379 \\
\hline 62 & Batrachuperus yenyuanensis & NC_012430 & 16394 \\
\hline 63 & Brachymystax lenok & NC_018341 & 16832 \\
\hline 64 & Brachymystax lenok tsinlingensis & NC_018342 & 16669 \\
\hline 65 & Brachymystax tumensis & NC_024674 & 16836 \\
\hline 66 & Hucho bleekeri & NC_015995 & 16997 \\
\hline 67 & Hucho hucho & NC_025589 & 16751 \\
\hline 68 & Hucho taimen & NC_016426 & 16833 \\
\hline 69 & Trichiurus lepturus nanhaiensis & NC_018791 & 17060 \\
\hline 70 & Trichiurus japonicus & NC_011719 & 16796 \\
\hline
\end{tabular}




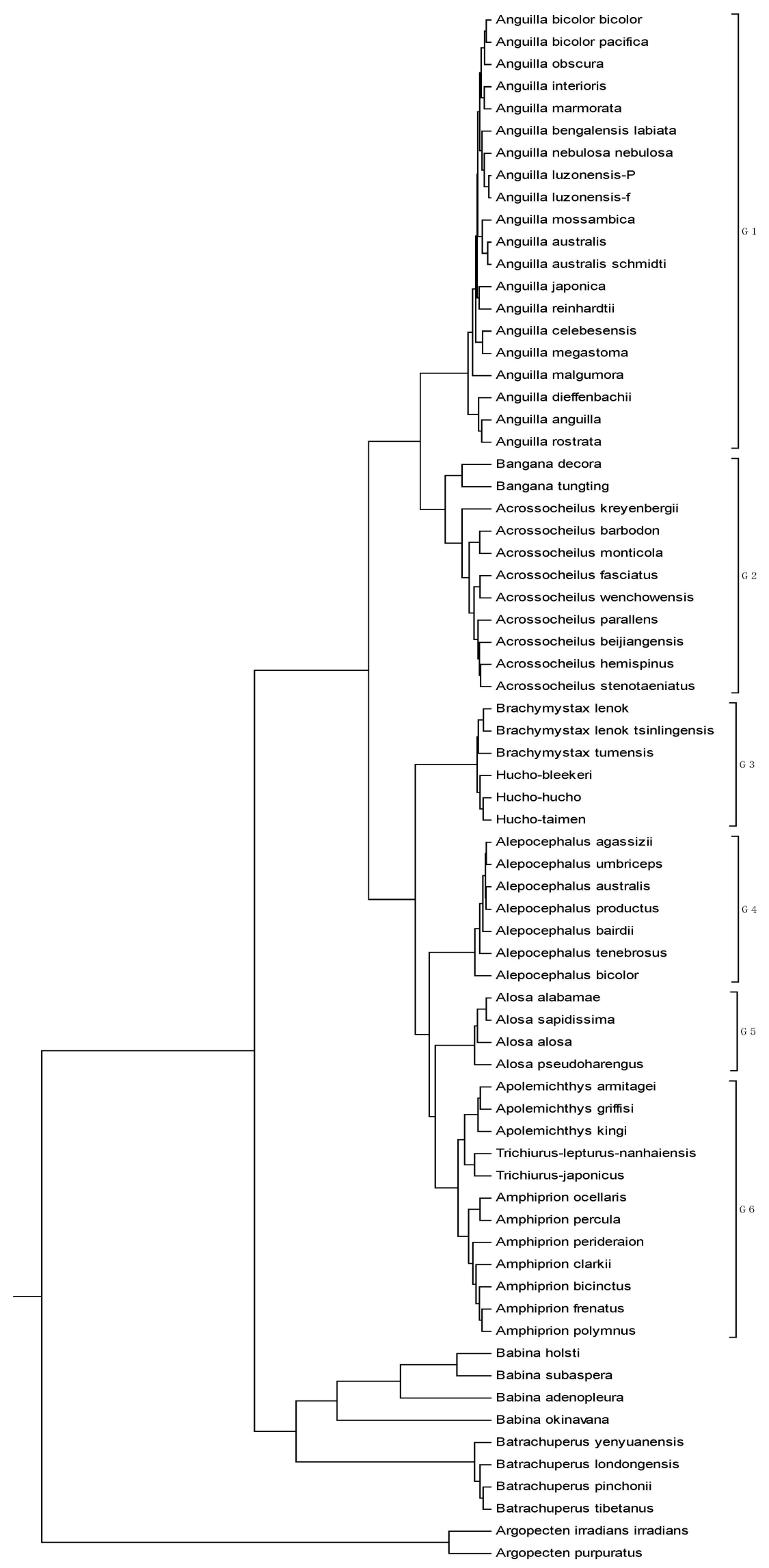

Figure 6. The tree of 70 genome sequences constructed with the current method. 


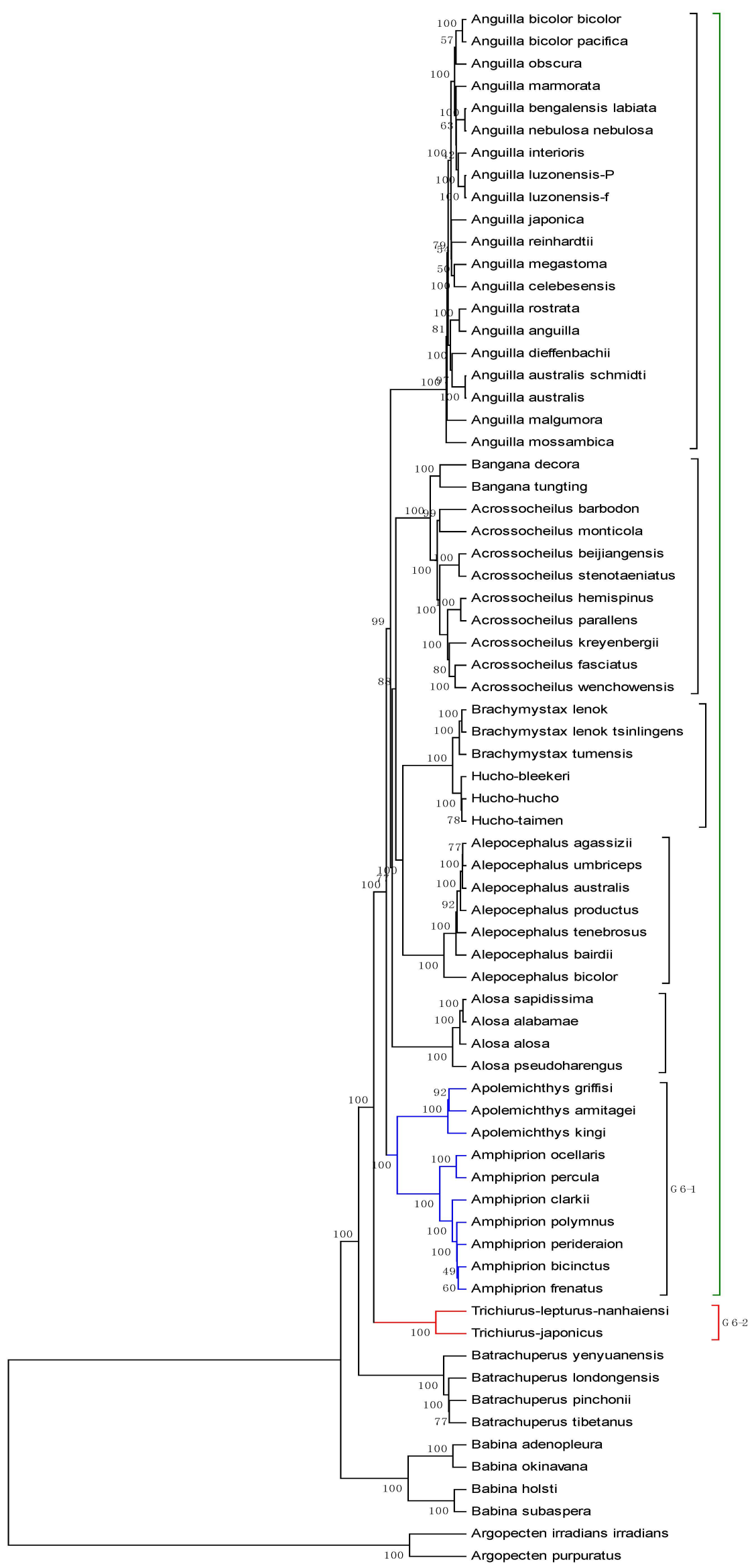

Figure 7. The tree of 70 genome sequences constructed with multiple alignment. 


\section{Concluding Remarks}

By means of a regular tetrahedron whose center is at the origin, we associate the ten 2-combinations of multiset $\{\infty \cdot A, \infty \cdot G, \infty \cdot C, \infty \cdot T\}$ with ten unit vectors (points on a unit sphere), and then a novel 3-D graphical representation of a DNA sequence is proposed. Moreover, we partition the graph into $K$ cells, and then a $3 K$-dimensional cell-based vector is used to numerically characterize a DNA sequence. The proposed method is tested by phylogenetic analysis on four datasets. In comparison with other methods, our approach does not depend on multiple sequence alignment, and avoids the complex calculation as in the calculation of invariants for higher order matrices. Nevertheless, $K$, the number of cells, is dataset specific, which may restrict our approach. We will make efforts in our future work to find a possible formula for $K$ that is independent of the dataset.

Acknowledgments: The authors wish to thank the three anonymous referees for their valuable suggestions and support. This work was partially supported by the National Natural Science Foundation of China (No. 11171042), the Program for Liaoning Innovative Research Team in University (LT2014024), the Liaoning BaiQianWan Talents Program (2012921060), and the Open Project Program of Food Safety Key Lab of Liaoning Province (LNSAKF2011034).

Author Contributions: Chun Li and Xiaoqing Yu conceived the study and drafted the manuscript. Wenchao Fei and Yan Zhao participated in the design of the study and analysis of the results.

Conflicts of Interest: The authors declare no conflict of interest.

\section{References}

1. Tian, K.; Yang, X.Q.; Kong, Q.; Yin, C.C.; He, R.L.; Yau, S.S.T. Two dimensional Yau-hausdorff distance with applications on comparison of DNA and protein sequences. PLOS ONE 2015, 10. [CrossRef] [PubMed]

2. Hamori, E.; Ruskin, J. H curves, a novel method of representation of nucleotide series especially suited for long DNA sequences. J. Biol. Chem. 1983, 258, 1318-1327. [PubMed]

3. Gates, M.A. Simpler DNA sequence representations. Nature 1985, 316. [CrossRef]

4. Nandy, A. A new graphical representation and analysis of DNA sequence structure: I methodology and application to globin genes. Curr. Sci. 1994, 66, 309-314.

5. Nandy, A. Graphical representation of long DNA sequences. Curr. Sci. 1994, 66, 821.

6. Leong, P.M.; Morgenthaler, S. Random walk and gap plots of DNA sequences. Comput. Appl. Biosci. 1995, 11, 503-507. [CrossRef] [PubMed]

7. Jeffrey, H.J. Chaos game representation of gene structure. Nucleic Acids Res. 1990, 18, 2163-2170. [CrossRef] [PubMed]

8. Randic, M.; Vracko, M.; Nandy, A.; Basak, S.C. On 3-D graphical representation of DNA primary sequences and their numerical characterization. J. Chem. Inf. Comput. Sci. 2000, 40, 1235-1244. [CrossRef] [PubMed]

9. Randic, M.; Novic, M.; Plavsic, D. Milestones in graphical bioinformatics. Int. J. Quantum Chem. 2013, 113, 2413-2446. [CrossRef]

10. Randic, M.; Zupan, J.; Balaban, A.T.; Vikic-Topic, D.; Plavsic, D. Graphical representation of proteins. Chem. Rev. 2011, 111, 790-862. [CrossRef] [PubMed]

11. Li, C.; Tang, N.N.; Wang, J. Directed graphs of DNA sequences and their numerical characterization. J. Theor. Biol. 2006, 241, 173-177. [CrossRef] [PubMed]

12. Yang, Y.; Zhang, Y.Y.; Jia, M.D.; Li, C.; Meng, L.Y. Non-degenerate graphical representation of DNA sequences and its applications to phylogenetic analysis. Comb. Chem. High Throughput Screen. 2013, 16, 585-589. [CrossRef] [PubMed]

13. Gonzzlez-Diaz, H.; Perez-Montoto, L.G.; Duardo-Sanchez, A.; Paniagua, E.; Vazquez-Prieto, S.; Vilas, R.; Dea-Ayuela, M.A.; Bolas-Fernandez, F.; Munteanu, C.R.; Dorado, J.; et al. Generalized lattice graphs for 2D-visualization of biological information. J. Theor. Biol. 2009, 261, 136-147. [CrossRef] [PubMed]

14. Zhang, Z.J. DV-Curve: A novel intuitive tool for visualizing and analyzing DNA sequences. Bioinformatics 2009, 25, 1112-1117. [CrossRef] [PubMed]

15. Qi, Z.H.; Jin, M.Z.; Li, S.L.; Feng, J. A protein mapping method based on physicochemical properties and dimension reduction. Comput. Biol. Med. 2015, 57, 1-7. [CrossRef] [PubMed] 
16. Waz, P.; Bielinska-Waz, D. 3D-dynamic representation of DNA sequences. J. Mol. Model. 2014, 20. [CrossRef] [PubMed]

17. Yao, Y.H.; Yan, S.; Han, J.; Dai, Q.; He, P.A. A novel descriptor of protein sequences and its application. J. Theor. Biol. 2014, 347, 109-117. [CrossRef] [PubMed]

18. Ma, T.T.; Liu, Y.X.; Dai, Q.; Yao, Y.H.; He, P.A. A graphical representation of protein based on a novel iterated function system. Phys. A 2014, 403, 21-28. [CrossRef]

19. Zhang, R.; Zhang, C.T. A brief review: The Z curve theory and its application in genome analysis. Curr. Genom. 2014, 15, 78-94. [CrossRef] [PubMed]

20. Zhang, C.T.; Zhang, R.; Ou, H.Y. The Z curve database: A graphic representation of genome sequences. Bioinformatics 2003, 19, 593-599. [CrossRef] [PubMed]

21. Zhang, R.; Zhang, C.T. Z curves, an intuitive tool for visualizing and analyzing DNA sequences. J. Biomol. Struct. Dyn. 1994, 11, 767-782. [CrossRef] [PubMed]

22. Herisson, J.; Payen, G.; Gherbi, R. A 3D pattern matching algorithm for DNA sequences. Bioinformatics 2007, 23, 680-686. [CrossRef] [PubMed]

23. Bianciardi, G.; Borruso, L. Nonlinear analysis of tRNAs squences by random walks: Randomness and order in the primitive information polymers. J. Mol. Evol. 2015, 80, 81-85. [CrossRef] [PubMed]

24. Ghosh, A.; Nandy, A. Graphical representation and mathematical characterization of protein sequences and applications to viral proteins. Adv. Protein Chem. Struct. Biol. 2011, 83. [CrossRef]

25. Karlin, S.; Burge, C. Dinucleotide relative abundance extremes: A genomic signature. Trends Genet. 1995, 11, 283-290. [PubMed]

26. Karlin, S. Global dinucleotide signatures and analysis of genomic heterogeneity. Curr. Opin. Microbiol. 1998, 1, 598-610. [CrossRef]

27. Yang, X.W.; Wang, T.M. Linear regression model of short $k$-word: A similarity distance suitable for biological sequences with various lengths. J. Theor. Biol. 2013, 337, 61-70. [CrossRef] [PubMed]

28. Li, C.; Ma, H.; Zhou, Y.; Wang, X.; Zheng, X. Similarity analysis of DNA sequences based on the weighted pseudo-entropy. J. Comput. Chem. 2011, 32, 675-680. [CrossRef] [PubMed]

29. Rocha, E.P.; Viari, A.; Danchin, A. Oligonucleotide bias in Bacillus subtilis: General trends and taxonomic comparisons. Nucleic Acids Res. 1998, 26, 2971-2980. [CrossRef] [PubMed]

30. Pride, D.T.; Meineramann, R.J.; Wassenaar, T.M.; Blaser, M.J. Evolutionary implications of microbial genome tetranucleotide frequency biases. Genome Res. 2003, 13, 145-158. [CrossRef] [PubMed]

31. Li, C.; Wang, J. Numerical characterization and similarity analysis of DNA sequences based on 2-D graphical representation of the characteristic sequences. Comb. Chem. High. Throughput Screen. 2003, 6, 795-799. [CrossRef] [PubMed]

32. Li, C.; Wang, J. New invariant of DNA sequences. J. Chem. Inf. Model. 2005, 36, 115-120. [CrossRef] [PubMed]

33. Bai, F.; Zhang, J.; Zheng, J.; Li, C.; Liu, L. Vector representation and its application of DNA sequences based on nucleotide triplet codons. J. Mol. Graph. Model. 2015, 62, 150-156. [CrossRef] [PubMed]

34. MEGA, Molecular Evolutionary Genetics Analysis. Available online: http://www.megasoftware.net (accessed on 15 January 2014).

35. Wang, J.; Shang, S.Q.; Zhang, Y.L. Phylogenetic relationship of genus catopsilia (Lepidoptera: Pieridae) based on partial sequences of NDI and COI genes from China. Acta. Zootaxon. Sin. 2010, 35, 776-781.

36. Zhang, Y.Z.; Dong, X.; Li, X.; Ma, C.; Xiong, H.P.; Yan, G.J.; Gao, N.; Jiang, D.M.; Li, M.H.; Li, L.P.; et al. Seoul virus and hantavirus disease, Shenyang, People's Republic of China. Emerg. Infect. Dis. 2009, 15, 200-206. [CrossRef] [PubMed]

37. Yao, P.P.; Zhu, H.P.; Deng, X.Z.; Xu, F.; Xie, R.H.; Yao, C.H.; Weng, J.Q.; Zhang, Y.; Yang, Z.Q.; Zhu, Z.Y. Molecular evolution analysis of hantaviruses in Zhejiang province. Chin. J. Virol. 2010, 26, 465-470.

38. Clustal: Multiple Sequence Alignment. Available online: http://www.clustal.org (accessed on 31 August 2012).

(C) 2016 by the authors; licensee MDPI, Basel, Switzerland. This article is an open access article distributed under the terms and conditions of the Creative Commons by Attribution (CC-BY) license (http:/ / creativecommons.org/licenses/by/4.0/). 